08,03

\title{
Влияние дозы имплантации и длительности отжига на люминесцентные свойства (113) дефектов в $\mathrm{Si}$, имплантированном ионами кислорода
}

\author{
(C) Н.А. Соболев ${ }^{1}$, А.Е. Калядин ${ }^{1}$, П.Н. Аруев ${ }^{1}$, В.В. Забродский ${ }^{1}$, \\ Е.И. Шек ${ }^{1}$, К.Ф. Штельмах ${ }^{1,2}$, К.В. Карабешкин ${ }^{1}$ \\ ${ }^{1}$ Физико-технический институт им. А.Ф. Иофффе РАН, \\ Санкт-Петербург, Россия \\ ${ }^{2}$ Санкт-Петербургский политехнический университет Петра Великого, \\ Санкт-Петербург, Россия \\ E-mail: nick@sobolev.ioffe.rssi.ru
}

(Поступила в Редакцию 18 мая 2016 г.

В окончательной редакции 14 июня 2016 г.)

Исследованы фотолюминесцентные свойства (113) дефектов, образующихся в Si-структуре после имплантации ионов кислорода с энергией $350 \mathrm{keV}$ и дозами $1.7 \cdot 10^{13}-1.7 \cdot 10^{15} \mathrm{~cm}^{-2}$ и последующего отжига при $700^{\circ} \mathrm{C}$ в течение $0.5-2 \mathrm{~h}$ в хлорсодержащей атмосфере. Независимо от дозы имплантации и времени отжига в спектрах фотолюминесценции доминирует линия с длиной волны $1.37 \mu \mathrm{m}$, принадлежащая (113) дефекту. Зависимости интенсивности линии от дозы имплантации и длительности отжига характеризуются кривыми с максимумами. С ростом температуры измерения в диапазоне $64-120 \mathrm{~K}$ интенсивность линии монотонно уменьшается.

Работа Н.А. Соболева и К.В. Карабешкина частично поддержана грантом РФФИ № 14-08-01256, а работа Е.И. Шек - грантом РФФИ № 14-02-00152.

\section{1. Введение}

Отсутствие инфракрасных светодиодов и лазеров на основе монокристаллического кремния с высокой интенсивностью электролюминесценции при комнатной температуре существенно сдерживает создание интегральных оптоэлектронных схем для кремниевой оптоэлектроники. Долгое время наблюдаемая низкая интенсивность собственной зона-зонной (так называемой краевой или near band edge) люминесценции объяснялась тем обстоятельством, что кремний является не прямозонным полупроводником. Развитие методов инженерии дефектов в кремниевой технологии позволило создать светодиоды с высокими интенсивностью и внешней квантовой эффективностью электролюминесценции (порядка 1\%) при комнатной температуре [1]. Однако такое излучение не может распространяться на достаточную глубину в кремнии из-за сильного поглощения. За последние двадцать лет было развито много технологических приемов, использующих как примесные атомы, так и собственные дефекты решетки кремния, для создания люминесцентных центров с длиной волны в диапазоне 1.2-1.7 $\mu \mathrm{m}$ [2]. Наибольшие интенсивность и эффективность электролюминесценции при комнатной температуре были достигнуты в светодиодах с люминесценцией редкоземельных ионов $\mathrm{Er}^{3+}[3,4]$ и так называемой дислокационной люминесценцией, обусловленной введением протяженных структурных дефектов [5,6]. Максимум длины волны излучения при комнатной температуре находится в области $1.5-1.7 \mu \mathrm{m}$. В последнее время предпринима- лись попытки использовать в качестве люминесцентных центров так называемые (113) дефекты [7], представляющие собой скопления собственных межузельных атомов со структурой, не отвечающей структуре дислокационных диполей и петель, и излучающие на длине волны $1.37 \mu \mathrm{m}$ [8-11]. Дефекты создавались с помощью имплантации ионов $\mathrm{Si}^{+}$и последующих отжигов в инертной атмосфере [8-11]. Фотолюминесценция (ФЛ) (113) дефектов в таких образцах наблюдалась до $40 \mathrm{~K}$. В настоящей работе исследованы люминесцентные свойства (113) дефектов, образующихся в кремнии после имплантации ионов $\mathrm{O}^{+}$и последующего отжига, в зависимости от дозы имплантации, длительности отжига, температуры измерения и мощности накачки.

\section{2. Экспериментальные условия}

Исходные образцы представляли собой $p^{+}-n$-структуры на основе кремния $n$-типа проводимости, выращенного методом Чохральского, с удельным сопротивлением $4.5 \Omega \cdot \mathrm{cm}$, в которых с помощью диффузии примеси бора из газовой фазы формировался $p^{+}-n$-переход. Измеренные с помощью метода вторичной ионной масс-спектроскопии концентрация бора у поверхности и глубина $p^{+}-n$-перехода равнялись $\sim 10^{20} \mathrm{~cm}^{-3}$ и $\sim 50 \mathrm{~nm}$ соответственно. Со стороны $p^{+}-n$-перехода имплантировались ионы кислорода с энергией $350 \mathrm{keV}$ и неаморфизующими дозами $D_{1}=1.7 \cdot 10^{15} \mathrm{~cm}^{-2}, D_{2}=3.7 \cdot 10^{14} \mathrm{~cm}^{-2}, D_{3}=$ $=7.7 \cdot 10^{13} \mathrm{~cm}^{-2}$ и $D_{4}=1.7 \cdot 10^{13} \mathrm{~cm}^{-2}$. Имплантация 
проводилась при комнатной температуре под углом $7^{\circ}$, чтобы избежать эффекта каналирования. Проецированная длина пробега ионов $\mathrm{O}^{+}\left(R_{P}\right)$, рассчитанная с помощью программы SRIM [12], равна $790 \mathrm{~nm}$. Таким образом, основная часть ионов кислорода имплантировалась глубже $p^{+}-n$-перехода. Последующие отжиги, в процессе которых происходили перестройка структурных дефектов и формирование люминесцентных центров, проводились при температуре $700^{\circ} \mathrm{C}$ в течение $0.5,1,1.5$ и $2 \mathrm{~h}$ в хлорсодержащей атмосфере (ХCA), представляющей собой поток кислорода, насыщенный парами четыреххлористого углерода с молярной концентрацией $1 \%$. ФЛ возбуждалась твердотельным лазером на длине волны $532 \mathrm{~nm}$ (диаметр луча $\sim 2 \mathrm{~mm}$, интенсивность изменялась в диапазоне $2-52 \mathrm{~mW}$ ) и регистрировалась в области длин волн $1000-1650 \mathrm{~nm}$ в диапазоне температур $64-120 \mathrm{~K}$ с помощью автоматизированного монохроматора МДР-25 и InGaAs-фотоприемника. Образец помещался в криостат УТРЕКС (разработка Института физики НАН Украины, Киев, Украина), что позволяло поддерживать температуру с точностью $\pm 0.2 \mathrm{~K}$.

\section{3. Результаты и их обсуждение}

Измеренные при $78 \mathrm{~K}$ спектры ФЛ образцов, имплантированных ионами кислорода с энергией $350 \mathrm{keV}$ и дозой $D_{2}=3.7 \cdot 10^{14} \mathrm{~cm}^{-2}$ и отожженных при $700^{\circ} \mathrm{C}$ в ХCA в течение $0.5,1,1.5$ и $2 \mathrm{~h}$, представлены на рис. 1. После отжига в течение $0.5 \mathrm{~h}$ в спектре доминируют две широкие линии с максимумами при $\sim 1350$ и $\sim 1580 \mathrm{~nm}$, которые характерны для дефектов, образующихся главным образом из собственных междоузельных атомов кремния на начальной стадии отжига облученных образцов [2]. При увеличении длительности отжига в спектрах доминирует узкая линия

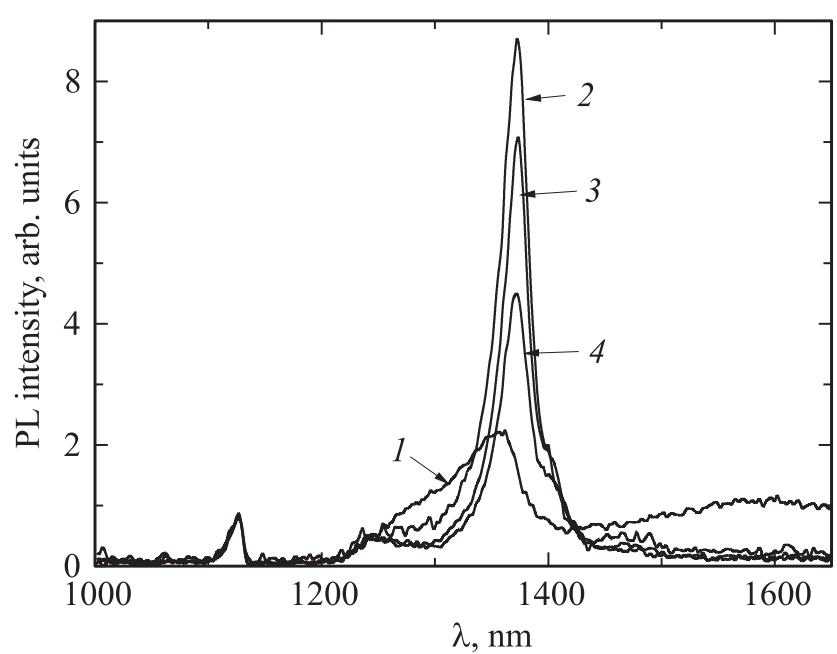

Рис. 1. Спектры ФЛ образцов, имплантированных ионами кислорода с энергией $350 \mathrm{keV}$ и дозой $D_{2}=3.7 \cdot 10^{14} \mathrm{~cm}^{-2}$ и отожженных при $700^{\circ} \mathrm{C}$ в ХСА в течение 0.5 (1), 1 (2), 1.5 (3) и $2 \mathrm{~h}(4)$. ФЛ измерялась при $78 \mathrm{~K}$.

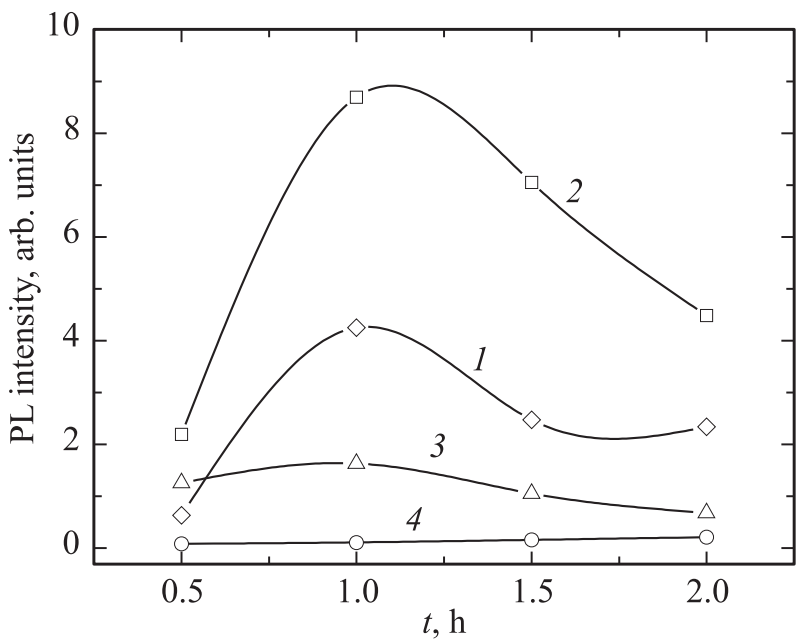

Рис. 2. Зависимости интенсивности линии ФЛ (113) дефектов от длительности отжига при $700^{\circ} \mathrm{C}$ в XCA для образцов, имплантированных ионами кислорода с энергией $350 \mathrm{keV}$ и дозами $D_{1}=1.7 \cdot 10^{15} \mathrm{~cm}^{-2}(1), D_{2}=3.7 \cdot 10^{14} \mathrm{~cm}^{-2}$ (2), $D_{3}=7.7 \cdot 10^{13} \mathrm{~cm}^{-2}(3)$ и $D_{4}=1.7 \cdot 10^{13} \mathrm{~cm}^{-2}(4)$. ФЛ измерялась при $78 \mathrm{~K}$.

с длиной волны $1372 \mathrm{~nm}$, которая принадлежит (113) дефекту [8-11]. Положение максимума линии при изменении времени отжига не меняется. Значения другого характерного параметра линии - ее полуширины, составляющие порядка $10 \mathrm{meV}$, достаточно хорошо коррелируют с приводимыми в литературе [8-11]. Максимальная интенсивность линии наблюдается после отжига в течение $1 \mathrm{~h}$. Исследование методами просвечивающей электронной микроскопии и электронной микроскопии высокого разрешения показало, что (113) дефекты доминируют в этом образце. С увеличением длительности отжига интенсивность линии уменьшается и начинает формироваться плечо (дополнительный пик) со стороны больших длин волн. Появление дополнительного пика ранее регистрировалось в имплантированных ионами кремния образцах при увеличении дозы имплантации [8]. Для всех отожженных образцов в спектрах ФЛ присутствует малоинтенсивная линия краевой (собственной) люминесценции при $1127 \mathrm{~nm}$.

Зависимости интенсивности линий ФЛ (113) дефектов от длительности отжига при $700^{\circ} \mathrm{C}$ в ХCA для образцов, имплантированных ионами кислорода с различными дозами, приведены на рис. 2. Измерения спектров ФЛ проводились при $78 \mathrm{~K}$. Уже при минимальной дозе имплантации $D_{4}=1.7 \cdot 10^{13} \mathrm{~cm}^{-2}$ формируются (113) дефекты, но интенсивность линии (113) практически не зависит от длительности отжига. При увеличении дозы имплантации и для всех длительностей отжигов интенсивность линии нарастает и достигает максимума при дозе $D_{2}=3.7 \cdot 10^{14} \mathrm{~cm}^{-2}$. При наибольшей дозе $D_{1}=1.7 \cdot 10^{15} \mathrm{~cm}^{-2}$ интенсивность уменьшается. Зависимости интенсивности линий (113) от длительности отжига при дозах имплантации $7.7 \cdot 10^{13}-1.7 \cdot 10^{15} \mathrm{~cm}^{-2}$ 


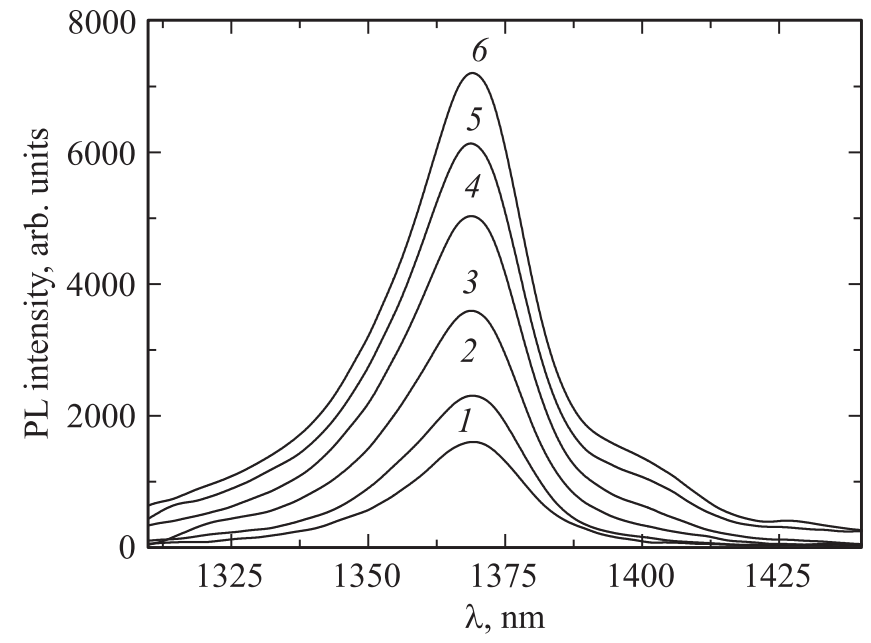

Рис. 3. Спектры ФЛ (113) дефектов в зависимости от мощности накачки для образцов, имплантированных ионами кислорода с энергией $350 \mathrm{keV}$ и дозой $D_{2}=3.7 \cdot 10^{14} \mathrm{~cm}^{-2}$ и отожженных при $700^{\circ} \mathrm{C}$ в течение $1 \mathrm{~h}$ в ХСА. ФЛ измерялась при $64 \mathrm{~K}$. Мощность накачки равна 2.1 (1), 4.3 (2), 10.7 (3), $21.5(4), 31(5)$ и $49 \mathrm{~mW}(6)$.

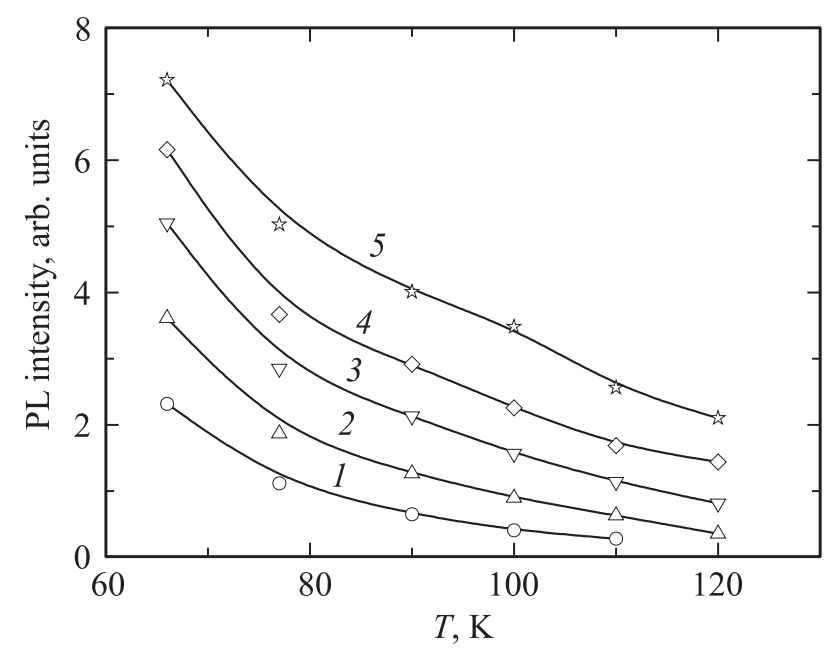

Рис. 4. Зависимости интенсивности линии ФЛ (113) дефектов от температуры измерения при различных мощностях накачки для образцов, имплантированных ионами кислорода с энергией $350 \mathrm{keV}$ и дозой $D_{2}=3.7 \cdot 10^{14} \mathrm{~cm}^{-2}$ и отожженных при $700^{\circ} \mathrm{C}$ в течение $1 \mathrm{~h}$ в ХСА. Мощность накачки составляет 4.4 (1), 10.7 (2), 22.7 (3), 33.5 (4) и $51.6 \mathrm{~mW}(5)$.

представляют собой кривые с максимумом при времени отжига $1 \mathrm{~h}$. Рост интенсивности с длительностью отжига обусловлен увеличением концентрации (113) дефектов, тогда как ее падение после $1 \mathrm{~h}$ отжига может быть связано как с уменьшением концентрации дефектов, так и с образованием эффективных центров безызлучательной рекомбинации.

Спектры ФЛ образцов, имплантированных ионами кислорода с энергией $350 \mathrm{keV}$ и дозой $D_{2}=$ $=3.7 \cdot 10^{14} \mathrm{~cm}^{-2}$ и отожженных при $700^{\circ} \mathrm{C}$ в XСА в течение $1 \mathrm{~h}$, были измерены в диапазоне длин волн $1310-1450 \mathrm{~nm}$ при $64 \mathrm{~K}$ и разной мощности накачки (рис. 3). Во всех спектрах доминирует линия ФЛ (113), интенсивность которой монотонно растет с увеличением мощности накачки. Полуширина линии, равная $\sim 10 \mathrm{meV}$, практически не зависит от мощности накачки. Положение максимума линии (113) дефекта не меняется при изменении мощности накачки и слабо зависит от температуры измерения в диапазоне $64-120 \mathrm{~K}$. При мощности накачки более $31 \mathrm{~mW}$ со стороны больших длин волн появляется дополнительный пик, который, по-видимому, принадлежит другому структурному дефекту, формирующемуся также главным образом из собственных междоузельных атомов кремния, но с меньшей скоростью, чем (113) дефекты.

Зависимости интенсивности линии ФЛ (113) дефектов от температуры измерения при мощностях накачки 4-52 mW для образцов, имплантированных ионами кислорода с энергией $350 \mathrm{keV}$ и дозой $D_{2}=3.7 \cdot 10^{14} \mathrm{~cm}^{-2}$ и отожженных при $700^{\circ} \mathrm{C}$ в течение $1 \mathrm{~h}$ в XCA, приведены на рис. 4. Интенсивность монотонно уменьшается с ростом температуры измерения при всех мощностях накачки. Линия ФЛ, принадлежащая (113) дефекту, впервые нами наблюдалась при $120 \mathrm{~K}$, что почти в 3 раза выше температуры, при которой она ранее регистрировалась в образцах, имплантированных ионами кремния [8-11]. Разумно ожидать, что при комнатной температуре ФЛ линии (113) может быть достигнута с применением методов геттерирования (например, фосфорного или алюминиевого) и водородной пассивации центров безызлучательной рекомбинации. Ранее было продемонстрировано, что использование этих методов увеличивает интенсивность линии ионов $\mathrm{Er}^{3+}$ и линии $D 1$ дислокационной люминесценции на два порядка величины $[5,13,14]$.

\section{4. Заключение}

В имплантированном ионами кислорода кремнии исследовано влияние условий формирования (дозы имплантации и длительности отжига) (113) дефектов и режимов измерения (температуры измерения и мощности накачки) на их люминесцентные свойства. Зависимости интенсивности ФЛ линии (113) от дозы имплантации и длительности отжига характеризуются кривыми с максимумами. Максимальная интенсивность достигается после имплантации с дозой $D_{2}=3.7 \cdot 10^{14} \mathrm{~cm}^{-2}$ и отжига в ХСА в течение $1 \mathrm{~h}$. Интенсивность ФЛ монотонно увеличивается с мощностью накачки и монотонно уменьшается с температурой. Положение максимума линии (113) дефекта не зависит от мощности накачки и слабо зависит от температуры измерения в диапазоне $64-120 \mathrm{~K}$. Значения полуширины линии в пластинах кремния, имплантированных ионами кислорода, близки к наблюдавшимся ранее в имплантированных ионами кремния образцах. Линия ФЛ (113) дефекта впервые 
наблюдалась при $120 \mathrm{~K}$, что почти в 3 раза выше температуры, при которой она ранее регистрировалась в имплантированных образцах. Полученные результаты дополняют и развивают существующие представления о люминесцентных свойствах (113) дефектов. Они также позволяют предположить, что в ближайшее время будут изготовлены работающие при комнатной температуре светодиоды с длиной волны $1370 \mathrm{~nm}$.

Авторы благодарны В.И. Вдовину за проведение исследований методами электронной микроскопии.

\section{Список литературы}

[1] M.A. Green, J. Zhao, A. Wang, P.J. Reece, M. Gal. Nature 412, 805 (2001).

[2] G. Davies. Phys. Rep. 176, 83 (1989).

[3] G. Franzo, F. Priolo, S. Coffa, A. Polman, A. Carnera. Appl. Phys. Lett. 64, 2235 (1994).

[4] A.M. Emel'yanov, N.A. Sobolev, A.N. Yakimenko. Appl. Phys. Lett. 72, 1223 (1998).

[5] V. Kveder, V. Badylevich, E. Steinman, A. Izotov, M. Zeibt, W. Schreter. Appl. Phys. Lett. 84, 2106 (2004).

[6] Н.А. Соболев, А.Е. Калядин, М.В. Коновалов, П.Н. Аруев, В.В. Забродский, Е.И. Шек, К.Ф. Штельмах, А.Н. Михайлов, Д.И. Тетельбаум. ФТП 50, 241 (2016).

[7] S. Takeda. Jpn. J. Appl. Phys. 30, L639 (1991).

[8] S. Coffa, S. Libertino, C. Spinella. Appl. Phys. Lett. 76, 321 (2000).

[9] P.K. Giri. Semicond. Sci. Technol. 20, 638 (2005).

[10] Y. Yang, C. Wang, R.D. Yang, L. Li, F. Xiong, J.M. Bao. Chin. Phys. B 18, 4906 (2009).

[11] Y. Yang, J.M. Bao, C. Wang, M.J. Aziz. J. Appl. Phys. 107, 123109 (2010)

[12] J.F. Ziegler, M.D. Ziegler, J.P. Biersack. Nucl. Instrum. Meth. B 268, 1818 (2010).

[13] J. Michel, J.L. Benton, R.F. Ferrante, D.C. Jacobson, D.J. Eaglesham, E.A. Fitzgerald, Y.-H. Xie, J.M. Poate, L.C. Kimerling. J. Appl. Phys. 70, 2672 (1991).

[14] E.O. Sveinbjornsson, J. Weber. Appl. Phys. Lett. 69, 2686 (1996). 